\title{
BDA calls on Sunak to set out action plan for service
}

The British Dental Association (BDA)

has called on the Chancellor to set out his response to a new report underlining the need for coherent support for dental services, particularly for mixed and private services. 1

The paper - the work of a short life working group bringing together a unique range of official and professional bodies - examines the national and local financial support packages currently available to dental practices. It sets out key recommendations, including calls for an extension of the Coronavirus Job Retention Scheme for the dental sector, lengthening the repayment period for government loans, and extension of business rates relief for dental practices.

The report hinges on wide ranging survey data gathered by the BDA that found in England:

- Two thirds of practices (66\%) are running at less than a quarter of pre-pandemic capacity
- $79 \%$ are likely or extremely likely to face financial difficulty in 3-6 months

- $54 \%$ lack confidence their practice could maintain current staffing levels in the coming year

- $78 \%$ determine 'fallow time' to be the greatest obstacle towards increasing activity levels.

In an open letter to Rishi Sunak the BDA has called on the department to set aside the 'boilerplate responses' and develop a coherent, funded plan to maintain the viability of the sector.

BDA Chief Executive Martin Woodrow said: 'Patient access to dentistry remains limited, and we face a real risk of deep health inequalities widening. The measured view of this paper is that a vital healthcare service - now operating at a fraction of its former capacity - requires urgent support.

'While short-term assistance has been offered to NHS contractors, private providers have largely had to go it alone.

'From the extension of business rates relief to ensuring necessary funding is in place to support services for vulnerable populations, the Treasury has a responsibility to take heed, and set out a clear plan to keep dentistry afloat.

'Since the onset of the pandemic we - and many MPs - have received mere boilerplate responses from the Treasury regarding support for dentistry. We've yet to see any real awareness of the unique challenges facing this service. We hope that this report will address this gap in understanding.'

\section{Reference}

1. BDA. Investigation into the resilience of mixed NHS/ Private dental practices following the first wave of the COVID-19 Pandemic. August 2020. Available at: https://www.bda.org/advice/Coronavirus/ Documents/Investigation-into-the-resilience-ofmixed-dental-practices-following-the-first-wave-ofthe-COVID-19-pandemic.pdf (accessed September 2020). 